\title{
Zeolites as an Element of Technological Units for Drying Solutions
}

\author{
Paranuk $\mathrm{AA}^{*}$ \\ Department ONGP, Kuban State Technological University, Russia \\ *Corresponding author: Paranuk AA, Department ONGP, FGBOU HPE, Kuban State Technological University, Russia.
}

Submission: 唖 December 03, 2017; Published: 些 August 31, 2018

\begin{abstract}
This paper describes the use of natural adsorbents of zeolites, as well as the prospects for their application in the non-chemical industry. It will be noted that thanks to the achievement of the chemical industry, new opportunities and applications for these adsorbents are being discovered.
\end{abstract}

Keywords: Zeolites; Sedimentary rocks; Separation of binary solutions; Molecular sieve properties

\section{Introduction}

In nature zeolites are widely distributed and often occur. They were formed because of changes in volcanic tuffs in the marine and continental basins and thus represent a tuffaceous-sedimentary type of deposits. The cat-ions that make up the zeolites can be replaced by ions of other metals under the action of the medium. Varying the conditions of hydrothermal synthesis and the course of cat-ion exchange reactions [1] under natural conditions predetermined a wide variety of types of natural zeolites.

The first samples of zeolite minerals were found in voids and cracks in basalts. The voids remained in place of the bubbles that arose during the cooling of the basalt mass, and the zeolites were formed later because of precipitation from solutions that drank basalts [2]. The chemical and physical factors that determined the character of the crystallization of these zeolites are complex and poorly understood. In some deposits, several periods of crystallization of zeolites can be detected.

In Northern Ireland, zeolite zones overlap with basalt strata; certain violations are associated with the shift of rocks. Apparently, the zeolites crystallized later than basalt, and their zones arose as a result of changes in the temperature or the chemical composition of water in the pores [2]. However, here, as everywhere, the composition of zeolites corresponds to the composition of the enclosing rocks. For example, modernize and other high-silica zeolites occur in rocks that are supersaturated with silica, while faujasite, shabasite, and other zeolites are predominantly found in silica-poor rocks.

Depending on the conditions of formation, zeolites in nature can be divided into two groups: endogenous and exogenous. Endogenous zeolites are usually dispersed in rocks and do not form large deposits suitable for use: the isolation of the mineral from the accompanying rock is associated with very large labor costs [1]. In addition, usually in this field there is not one, but several types of zeolites.

These circumstances for a long time prevented the widespread use of natural zeolites in industry. But the development of technologies in the field of extraction of natural zeolites was stimulated by the fact that large deposits of natural zeolites were discovered in many regions. The cost of their extraction is about 20 times lower than the cost of synthesis. Naturally, the involvement of cheap natural raw materials into industrial turnover seemed a very tempting task [3]. The unique adsorption properties of natural zeolites open new prospects for their use in industry. For example, in such a direction as drying of natural gas, water treatment, removal of nitrogen compounds from sewage. Thus, the scope of their application is very extensive. Due to the structure of the zeolite framework, most zeolites can be used as molecular sieves, which open a whole field of application of natural zeolites as cheap adsorbents in technological processes. For example: A method for separating an azeotropic solution by adsorption methods on natural zeolites.

The initial azeotropic solution (Figure 1) from the sump 1 for further processing is fed to the pipeline (1) by means of pumps (2) through the pipeline to the adsorbers with zeolite (3), the solution is pumped upwards through the adsorber unit into the pipe line (5). After saturating the adsorbent with a solution, it is necessary to switch the valves and stop the supply of pumps for regeneration of the zeolite. Regeneration of zeolite can be carried out in 2 ways. The first method is provided for the cases of realizations of this technological scheme in the conditions of the head compressor 
station with its own drying system with the help of solid absorbers, since in such schemes there is a natural gas heating furnace for own needs. Therefore, it is possible to use a portion of the regeneration gas for zeolite desorption. To realize the desorption stages, it is necessary to supply natural gas to the adsorber from top to bottom
(4) at a temperature $150-250^{\circ} \mathrm{C}$. After desorption, the mixture is fed to the separator, where the dripping moisture is taken off, and after the separator into the heat exchanger, where the gas is cooled, and then back to the adsorber for cooling. Thus, the system is closed.

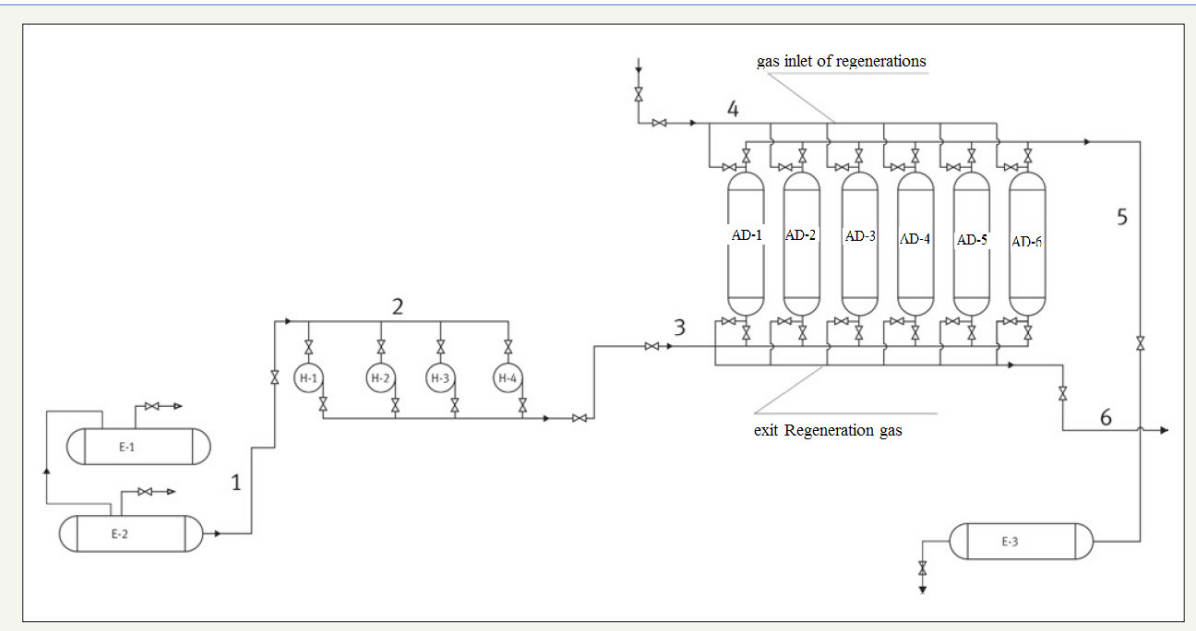

Figure 1: Installation of separation of multi component mixtures by adsorption methods on natural zeolites.

The second method involves the creation of an own plant for producing regeneration gas, since the zeolite is desorbed well at a temperature of $200-250{ }^{\circ} \mathrm{C}$. This scheme can be realized as follows: the unit for obtaining nitrogen from the air feeds nitrogen to the heater, after which nitrogen, heated to the required temperatures, is fed to the adsorber. After desorption, the mixture enters the separator, where the liquid fraction is beaten, and then enters the heat exchanger, where it is cooled to the required temperature, and then back to the adsorber to cool it.

It can be noted that when water is absorbed from an azeotropic solution with X-type zeolites containing alkali cat-ions, the first $\mathrm{H}_{2} \mathrm{O}$ molecules in all cases are adsorbed on non-localized cat-ions, which causes large adsorption heats [3]. As the size of the cat-ion grows in some alkali metals, the heats of adsorption decrease, although very unevenly-on zeolites ( $\mathrm{Li}, \mathrm{Na})-\mathrm{X}$ and $\mathrm{Na}-\mathrm{X}$, as on $(\mathrm{K}, \mathrm{Na})-\mathrm{X}$ and $(\mathrm{Rb}, \mathrm{Na})-\mathrm{X}$, the initial filling area they almost coincide [4].

In the case of zeolites (Li,Na)-X and $\mathrm{Na}-\mathrm{X}$, the energy of interaction of water molecules with cat-ions is significantly lower than the interaction energies with non-localized cat-ions. At the same time, for large cat-ions, which should be markedly put forward by their 6-membered rings [3] in large cavities, the screening by oxygen atoms plays a secondary role, and the energy of interaction with cat-ions depends little on the crystallographic positions cations. This manifests itself particularly clearly in the case of zeolite (Cs, Na)-X, whose heat of $\mathrm{H}_{2} \mathrm{O}$ adsorption remains practically constant in a very wide range of fillings. In this case, the optimal arrangement of $\mathrm{H}_{2} \mathrm{O}$ molecules is realized, at which the interaction with cat-ions and oxygen atoms of the lattice is possible at the same time [3].
Thus, the optimal designs for a process unit for the separation of an azeotropic solution by adsorption methods on natural zeolites are zeolites in which the cat-ions of the metals of potassium (K) and sodium $(\mathrm{Na})$ are included as the metal cat-ions in the crystal structure [5].

\section{Results}

The proposed method makes it possible to produce methanol regeneration by adsorption and return methanol technology for future use.

\section{Conclusion}

Thus, the reduced flow charts a new direction of the application of zeolite adsorbents with the use of molecular-sieve properties.

\section{References}

1. Keltsev (1984) NV basics of adsorption techniques. ( $2^{\text {nd }}$ edn), Revised and Additional, M: Chemistry, p. 592.

2. Donald WB (1973) Zeolite molecular sieves: Structure, chemistry, and use. John Wiley and Sons, New York, USA, p. 77.

3. Zhdanov SP, Khvoshchev SS, Samulevich NN (1981) Synthetic zeolites: Crystallization, structural chemical modification and adsorption properties. M Chemistry, p. 261.

4. Paranuk AA (2017) A mathematical model for calculating the adsorbers for drying and concentration of methanol on zeolites. Chemical and Petroleum Engineering 53(1-2): 41-43.

5. Paranuk AA, Klirisontdi VA (2016) Industrial application of molecular sieves. Inierakt Nauka 5: 51-53. 
(c) (i) Creative Commons Attribution 4.0 International License

For possible submissions Click Here

Submit Article

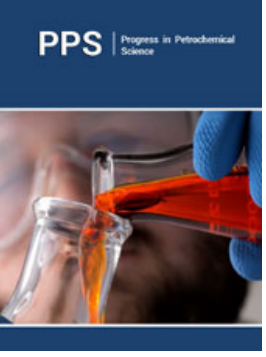

\section{Progress in Petrochemical Science}

Benefits of Publishing with us

- High-level peer review and editorial services

- Freely accessible online immediately upon publication

- Authors retain the copyright to their work

- Licensing it under a Creative Commons license

- Visibility through different online platforms 